\title{
The Influence of a Translucent Fiberglass Post on the Polymerization of Dual Cure Resin Cement Analyzed by Electron Paramagnetic Resonance
}

\author{
Fabio Martins Salomão ${ }^{a}$, Bruno Luiz Santana Vicentin ${ }^{b *}$ Edwin Fernando Ruiz Contreras ${ }^{c}$,
} Márcio Grama Hoeppnerc, Eduardo Di Mauro ${ }^{b}$

\author{
${ }^{a}$ Faculdade de Odontologia de Araçatuba, Universidade Estadual Paulista Júlio de Mesquita Filho - \\ UNESP, Rua José Bonifácio, 1193, CEP 16015-050, Araçatuba, SP, Brazil \\ ${ }^{b}$ Departamento de Física, Universidade Estadual de Londrina - UEL, Rod Celso Garcia Cid PR - 445, \\ Km 380, Campus Universitário, CEP 86057-970, Londrina, PR, Brazil \\ ${ }^{c}$ Departamento de Odontologia Restauradora, Universidade Estadual de Londrina - UEL, \\ Rua Pernambuco, 540, CEP 86020-120, Londrina, PR, Brazil
}

Received: June 30, 2015; Revised: July 17, 2015

\begin{abstract}
Electron Paramagnetic Resonance (EPR) was used as an alternative method to study the conversion degree of dual cure resin cement and verify the influence of prefabricated translucent fiberglass post on the dual cure resin cement polymerization at different restoration points. The post cementation of White Post DC (FGM, Joinville, SC, Brasil) was simulated using the dual cured resin cement Allcem (FGM, Joinville, SC, Brasil) in three different protocols: cement irradiated for $40 \mathrm{~s}$; no light irradiation and cement irradiated with sealed cementation line. $2 \mathrm{~mm}$ samples were obtained from three post sections and EPR spectra were obtained 10 minutes and 24 hours after mixing the base paste and catalyst of the cement. Results shows that the light curing protocol influenced the concentration of free radicals up to $8 \mathrm{~mm}$ of the restoration, and the capacity of light transmission of the post was significant for the first $8 \mathrm{~mm}$ of restoration and is non-existent in the deepest points of a simulated root canal. The cure in the apical part of restoration is exclusively chemical.
\end{abstract}

Keywords: EPR, photopolymerization, self-cure, light transmission, free radical

\section{Introduction}

In clinical situations where there is great coronal destruction, either by caries or dental trauma, both endodontic treatment and the use of a post and core technique are necessary to retain a restorative material ${ }^{1-4}$.

When compared to a traditional cast metal post, prefabricated fiberglass posts gained popularity due to their aesthetics, bonding to radicular dentin tissue and restorative material, low cost, non-corrosiveness, and having a modulus of elasticity similar to dentin, reducing the probability of radicular fracture ${ }^{1,5}$. In addition to the mechanical advantage, cementation with an adhesive material can improve the bond between the fiberglass post and the radicular dentin which, when effective, results in the formation of a homogeneous structure, known as mono bloc ${ }^{3,6}$.

When considering the polymerization reaction, the cementation of an intraradicular post can be performed using a chemically cured resin cement (self-curing), which polymerizes by mixing a base paste and a catalyst, or by using a dual cured resin cement (photoactivated and chemically cured $)^{7-9}$. However, the irradiation of light necessary to initiate the conversion of monomers into polymers is hindered by factors, such as root anatomic characteristics, power of the light emitted, distance from the curing light in relation to the cement, translucency of the post, amount

*e-mail: bsvicentin@gmail.com and position of fiber in the post, amount of filler in the post and cement, monomer type and cement opacity degree ${ }^{1,3,10}$. When the polymerization degree of the resin cement does not reach satisfactory levels, its mechanical properties are compromised $^{6,11,12}$. The initial concentration of free radicals is crucial to promote better clinical results and is directly connected to the degree of conversion of monomers to polymers ${ }^{13}$, so that the knowledge of the variables that affects the initial amount of free radicals generated is fundamental to de development of more efficient materials and technics.

The methacrylate radical generated during photopolymerization of dental restoration resins can be analyzed using Electron Paramagnetic Resonance (EPR) spectroscopy. EPR spectroscopy is a highly sensitive and nondestructive technique for identifying and quantifying the paramagnetic species in a sample (free radicals in this case) ) $^{13}$. EPR has been used to study the behavior of methacrylate radicals in numerous situations, including: irradiation at different wave length ${ }^{14}$, required polymerization time as a function of resin composition ${ }^{15}$ or sample thickness ${ }^{16}$, resin hardness as a function of the relative number of radicals ${ }^{17,18}$, degree of conversion ${ }^{19}$, translucence ${ }^{13,20-22}$, and molecular structure of the generated radicals ${ }^{23}$.

As the signal intensity of the EPR spectrum is proportional to the amount of free radicals in a sample, and considering that the translucency of some fiberglass posts provides the 
capacity to conduct light and contribute to the polymerization of the resin cement inside the root canal ${ }^{12,24,25}$, this current study evaluated the free radical concentration according to the depth into a simulated root canal to characterize the influence of the translucent fiberglass post on the polymerization of resin cement, and then its influence on cementation. We verified that the light transmission is effective in the first $8 \mathrm{~mm}$ of restoration, and sealing the cementation line effects the polymerization of the cement, decreasing the amount of free radicals generated to initiate the polymerization reaction.

\section{Experimental}

\subsection{Materials}

In this present experiment, the relative concentration of free radicals from the dual cure resin cement, Allcem (FGM, Joinville, SC, Brasil; Table 1) of shade A1 was evaluated by Electron Paramagnetic Resonance (EPR) at different restoration points, after cementation of a prefabricated translucent fiberglass post White Post DC Number 1 in a simulated root canal. These materials have properties and qualities that are very similar to others used worldwide. This methodology provides data and basement to understand the influence of a translucent fiberglass post on the degree of conversion of dual cure resin cement.

The experiment is divided in three major groups: irradiated for 40s (G1), not irradiated (G2) and irradiated for 40s with the cementing line sealed (G3). In all groups the post was cemented and then sectioned in three parts (Cervical, Middle and Apical Thirds). By means of the relative concentration of free radicals it is possible to study two variables: the influence of sealing the cementing line in the curing of the resin cement, and the influence of the fiber glass post in the polymerization of resin cement at different depths (depth of cure of translucent fiberglass post).

\subsection{Obtaining the simulated conduct}

Initially, a PVC (Polyvinyl chloride) tube with an $18 \mathrm{~mm}$ inner diameter was sectioned using a hydraulic mechanical lathe, to obtain nine rings that were $10 \mathrm{~mm}$ in height (Figure 1A). A polyacetal matrix, $25 \mathrm{~mm}$ in height and $18 \mathrm{~mm}$ in inner diameter, was fabricated using a hydraulic mechanical lathe. A $2.2 \mathrm{~mm}$ diameter hole was drilled in the center of the polyacetal matrix, along to its long axis, to a depth of $20 \mathrm{~mm}$. Subsequently, the polyacetal matrix was placed over the PVC ring (Figure 1B) and the Zetalabor (Hard. 85 shore-A, Zhermack, Badia Polesine, Rovigo, Italy) condensation cure silicon putty was inserted into the exposed hole of the polyacetal matrix, obtained from the mixture of base paste and catalyst according to manufacturer's recommendations. The entire internal space was filled and the PVC ring was positioned under pressure over a glass plate. Before silicone polymerization, a fiberglass post (White Post $\mathrm{DC} \mathrm{n}^{\circ} 3, \mathrm{FGM}$, Joinville, SC, Brasil) was inserted into the polyacetal matrix using a metal rod. The entire system: PVC ring, Polyacetal matrix, condensation cure silicon and the fiberglass post was maintained over the glass plate.

After the final cure of the silicon, the polyacetal matrix was removed, leaving the PVC ring, silicon and fiberglass post (Figure 1C). $18 \mathrm{~mm}$ of the $20 \mathrm{~mm}$ long fiberglass post was contained in the molding material and $2 \mathrm{~mm}$ remained exposed, simulating the clinical process of fiberglass post cementation inside a root canal. The fiberglass post remained in position for 24 hours.

The White Post DC $\mathrm{n}^{\circ} 3$ fiberglass post was removed to obtain a cementation path for the fiberglass post (Figure 1D), White Post DC $\mathrm{n}^{\circ} 1$ (FGM, Joinville, SC, Brasil), in the condensation cure silicone, with dimensions and shape similar to those of the No. 3 fiberglass post (Table 2).

\subsection{Obtaining the samples}

Prior to cementation, the $\mathrm{n}^{\mathrm{o}} 1$ fiberglass post surface was cleaned with 70\% alcohol and Prosil Silane (FGM, Joinville, $\mathrm{SC}$, Brasil) was applied and allowed to sit for 1 minute to allow for evaporation and drying.

The resin cement used in this experiment was the dual cure resin cement, Allcem (FGM, Joinville, SC, Brasil), color shade A1, composed of base paste and catalyst. Disposable auto-mixing points, which were provided by the manufacturer, were utilized to mix in a proportion of $1: 1$ by weight. The mixture was inserted into the silicone using

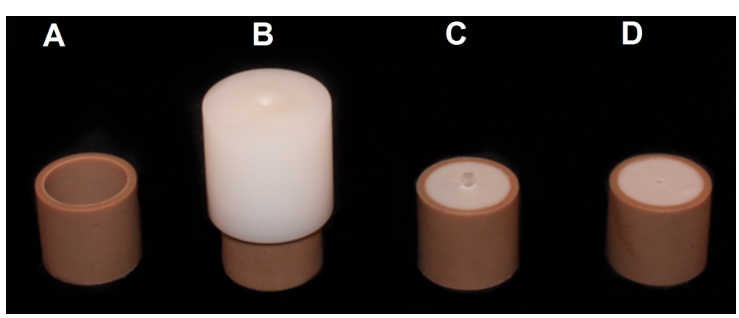

Figure 1. Matrices and system guides. A) PVC ring; B) Polyacetal matrix placed over PVC ring; C) Set PVC, ring, silicon and fiberglass post White Post $\mathrm{DC}^{\circ}{ }^{\circ}$ 3; D) Simulated conduct matrix.

Table 1. Experimental groups and material evaluated.

\begin{tabular}{|c|c|c|c|}
\hline Group & Sample & Treatment & Factor to be assessed \\
\hline G1 & $\begin{array}{ll}3 \text { translucent fiberglass posts } & 3 \text { sections of the cervical third } \\
\text { White Post DC (FGM), } & 3 \text { sections of the middle third } \\
\text { number 1 } & 3 \text { sections of the apical third }\end{array}$ & Irradiated (40s) & $\begin{array}{l}\text { FR concentration of the } \\
\text { cement A1lcem (FGM) } \\
10 \text { minutes (T0) and } 24 \text { hours }\end{array}$ \\
\hline $\mathrm{G} 2$ & $\begin{array}{ll}3 \text { translucent fiberglass posts } & 3 \text { sections of the cervical third } \\
\text { White Post DC (FGM), } & 3 \text { sections of the middle third } \\
\text { number } 1 & 3 \text { sections of the apical third }\end{array}$ & Not irradiated & (T1) after the cement mixture \\
\hline G3 & $\begin{array}{l}3 \text { translucent fiberglass posts } 3 \text { sections of the cervical third } \\
\text { White Post DC (FGM), } \\
\text { number } 1\end{array}$ & $\begin{array}{l}\text { Irradiated }(40 \mathrm{~s}) \text { with the } \\
\text { cementing line sealed }\end{array}$ & \\
\hline
\end{tabular}


Table 2. Fiberglass post dimensions.

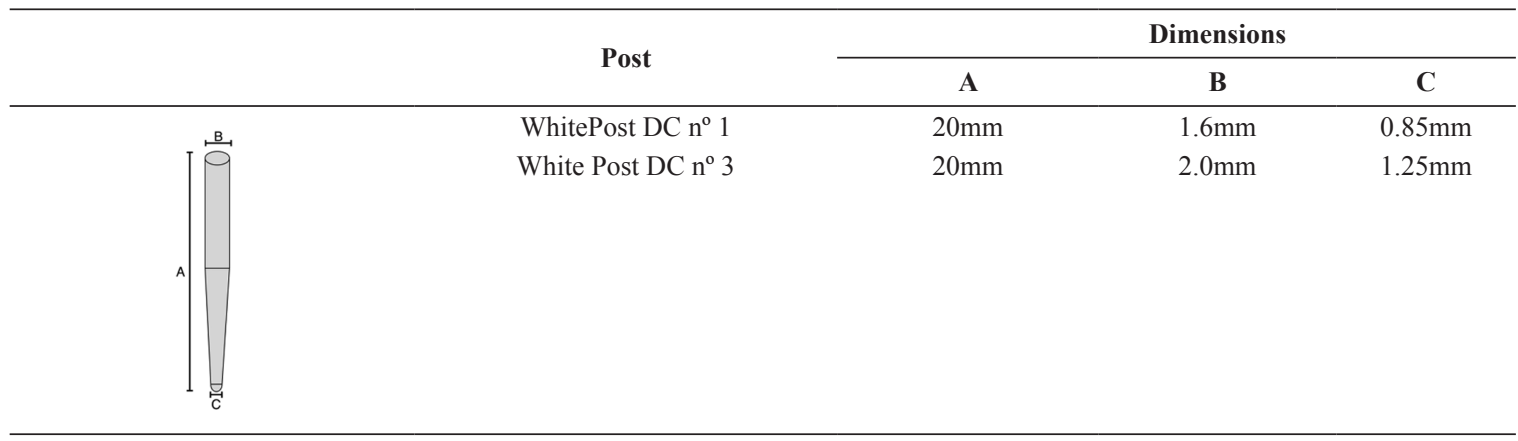

a Centrix Syringe (DFL, Rio de Janeiro, RJ, Brasil) with the deposable AccuDose Needle. The $n^{\circ} 1$ WhitePost DC fiberglass post was inserted (cemented) into the condensation cure silicon along the long axis. Extra cement was removed using a disposable micro-applicator (Cavibrush $n^{\circ} 2, F_{\text {GM, }}$ Joinville, SC, Brasil).

After the post cementation for groups 1 and 3, the resin cement was photopolymerized for 40 seconds using a light emitting diode (LED) (Radii Plus - SDI ${ }^{\circledR}$, São Paulo, SP) with $1,500 \mathrm{~mW} / \mathrm{cm}^{2}$ potency and in contact with the exposed fiberglass post $(2 \mathrm{~mm})$. In $\mathrm{G} 3$, the junction between the post and silicone interface was sealed prior to light curing to block light in this region. The resin cement was not photopolymerized after post cementation in G2.

After 10 minutes from the resin cement mixture, was all specimens were removed from the silicone and the $2 \mathrm{~mm}$ section of the fiberglass post that extended from the specimens were sectioned using a double-sided fine-grained diamond disc (Microdont, Socorro, SP, Brasil) at low speed. This sectioning left $18 \mathrm{~mm}$ of the post that was cemented, which was divided into three equal parts ( $6 \mathrm{~mm}$ each): the cervical third (closest to the silicon external surface), middle third, and apical third (furthest from the silicon external surface). A $2 \mathrm{~mm}$ sample from each third was obtained to study the relative concentration of free radicals: cervical third (CT), middle third (MT) and apical third (AT) (Figure 2).

\subsection{Electron Paramagnetic Resonance (EPR) spectroscopy}

The polymerization process of resin cements occurs by addition of free radicals and takes place in three stages: initiation, chain propagation and termination. In the initiation stage methacrylate radicals are generated by the absorption of blue visible light (in the case of photo-cure) and by the decomposition of benzoyl peroxide (BPO) (in the case of self-cure). In the propagation stage those free radicals reacts with monomers initiating the chain reaction by the addition of monomers to the chain. The termination occurs by combination of active monomers ${ }^{7-9}$. As the free radical molecule possesses an unpaired electron, this molecule is a paramagnetic specie, and so by EPR spectroscopy it is possible to evaluate the concentration of free radicals for dental resins and resin cements.

The paramagnetic species are characterized as having an unpaired electron, which interacts with the external magnetic field generated by a coil to split the electron spin

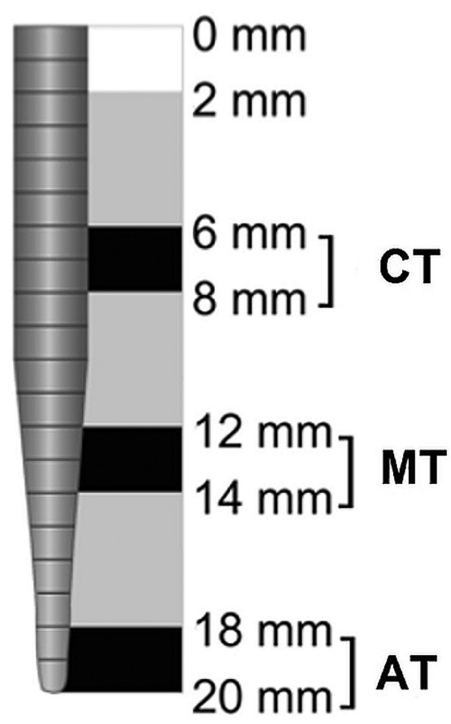

Figure 2. Schematic representation of the $\mathrm{n}^{\mathrm{o}} 1$ White Post DC fiberglass post sections, where "CT" is the Cervical Third, "MT" is the Medium Third and "AT" is the Apical Third.

state. The unpaired electron absorbs the incident microwave radiation and undergoes spin state transition. The absorption of incident microwave radiation in a varying magnetic field is detected and the amplitude of the absorption signal is proportional to the amount of unpaired electrons in the sample. In fact, the EPR spectrum is the first derivative of the microwave absorption curve.

In this current study, the EPR spectrum was analyzed concerning the signal amplitude to evaluate the relative concentration of free radicals according to the depth of the simulated root canal to characterize the influence of the translucent fiberglass post on the dual cure resin cement polymerization. The influence of the polymerization protocol was investigated using this technique as well.

Figure 3 shows the superposition of EPR spectra for CT, MT and AT of G1, and illustrates how the comparison can be done. As CT showed the most intense EPR signal amplitude and thus the greatest concentration of free radicals for all experimental groups, it was taken as the reference point to study the variation on the relative concentration of free radicals between the samples in the group, so that the data presentation is relative to CT (taken as 100\%) in 
each group. The first line in the EPR spectrum (Figure 3) is the superposition of the $3^{\text {th }}$ line of the $\mathrm{MgO}: \mathrm{Mn}^{2+}$ standard (called Mn3) with the first line of the free radical (called $\mathrm{R} 1$ ), and the last line in the spectrum is the superposition of the $4^{\text {th }}$ line of the standard $(\mathrm{Mn} 4)$ with the $9^{\text {th }}$ line of the free radical (R9). The EPR signal intensity of free radicals for all groups was normalized with the line intensity of the 3rd line of the $\mathrm{MgO}: \mathrm{Mn} 2+$ standard to compare variances in the intensity of the free radical signal (central line) because the superposition is very small and does not change final intensity. As the replicates showed the same results we used the samples with best signal to noise ratio for data treatment.

EPR spectra in X-band ( $\sim 9 \mathrm{GHz})$ were obtained using a JEOL (JES-PE-3X) spectrometer at room temperature, and the microwave power $(1 \mathrm{~mW})$, modulation amplitude (20 Gauss) and modulation frequency (100 KHz) were set to avoid signal saturation. A JEOL standard sample $\mathrm{MgO}: \mathrm{Mn}^{2+}$ was used as an intensity standard and g marker to determine the relative concentration of free radicals. The $2 \mathrm{~mm}$ samples from each third of fiberglass posts were inserted into quartz tubes with a $3 \mathrm{~mm}$ inner diameter and were analyzed 10 minutes (T0) and 24 hours (T1) after cement mixing. In the time interval from $\mathrm{T} 0$ to $\mathrm{T} 1$, the samples were stored in aluminum envelopes to remove any influence of external radiation. The data obtained were processed using Origin 8 (OriginLab) and EasySpin (MatLab) software to process the EPR spectra. The estimated error in determining the intensity peak is .

\section{Results and Discussion}

The EPR spectrum in Figure 3 shows nine lines characteristic of hyperfine interactions. It is concluded that the paramagnetic species in the sample are the "propagating" and "allylic" radicals shown by Fontes et al. ${ }^{23}$, which generated during the irradiation of the sample. These radicals are present in the sample even one month after the irradiation because of the vitrification phenomenon, although in much less concentration $^{13}$. The reaction kinetics of dental materials is dependent on the initial concentration of monomers and initiators, as well as the light intensity and depth of cure and temperature $^{26}$. This supports the analysis in two different days and light intensity in this study.

\subsection{The influence of irradiation protocol}

In relation to the amount of free radicals generated using different initiation methods, the present resin cement displayed a dependence of this quantity with the sample irradiation protocols (Table 3). The chemical cure occurs regardless of the physical cure, a fact verified by the EPR spectrum for the generated free radicals. Similar results were reported by Leprince et al. ${ }^{22}$ when evaluating free radical concentrations in a composite resin using different polymerization protocols and EPR.

In relation to the different irradiation protocols, G1 showed the strongest EPR spectrum signal at T0 and for the CT, with a value of $100 \%$, with all other samples being compared with this result. The concentration of free radicals for $\mathrm{G} 2$ at the $\mathrm{CT}$ was equivalent to $53 \%$ from $\mathrm{G} 1$, and $87 \%$ from G3. Regarding the samples from the middle and apical thirds for all groups, the variation in the intensity of

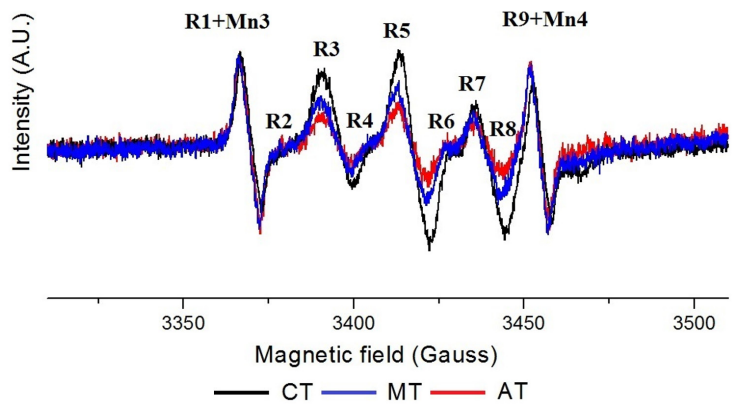

Figure 3. Free radical EPR spectrum of CT, MT and AT of G1 with a $\mathrm{MgO}: \mathrm{Mn}^{2+}$ standard sample.

Table 3. Relative concentration of free radicals in the samples 10 min after mixing base paste and catalyst.

\begin{tabular}{cccc}
\hline \multirow{2}{*}{ Group } & \multicolumn{3}{c}{ Sample } \\
\cline { 2 - 4 } & CT & MT & AT \\
\hline G1 & $100 \pm 6 \%$ & no varies & no varies \\
G2 & $53 \pm 6 \%$ & no varies & no varies \\
G3 & $87 \pm 6 \%$ & no varies & no varies \\
\hline
\end{tabular}

the EPR spectrum was not significant, indicating that the radiation did not influence the free radical formation in the depth correspondent to G1 and G3. Comparatively to G1, the EPR spectrum intensity reduction was $47 \%$ for CT in $\mathrm{G} 2$ and $13 \%$ in G3 (Table 3). These results are corroborated by Mallman et al. ${ }^{24}$, who observed higher bond strengths in the cervical radicular third when compared to the middle and apical thirds using translucent and opaque fiberglass posts, and by Leprince et al. ${ }^{22}$, who observed greater free radical concentrations when using the same photopolymerization protocol.

The decrease observed in the relative concentration of free radicals for CT in G2 (Table 3) was significant when compared to $\mathrm{G} 1$ and $\mathrm{G} 3$, because the cement polymerization in $\mathrm{G} 2$ was exclusively chemical. When compared to $\mathrm{G} 1$, the observed decrease for CT in G3 might have occurred due to the use of a barrier at the post-silicon interface, which limited the passage of the curing light to only through the post ${ }^{12,20,21}$.

Comparing G1 and G3 for CT, the light emitted may have been absorbed and transmitted by the cement located at the post-silicone interface, indicating that sealing the cementing line can diminish the initial amount of generated free radicals effecting the conversion degree of monomers to polymer.

It is possible to notice that the translucence and light conduction capability of the post is significant only in the firs $8 \mathrm{~mm}$ of restoration, once the irradiation protocol did not interfere in the amount of generated free radicals for MT and AT.

\subsection{Depth of cure of the translucent fiberglass post}

The influence that chemical and physical polymerization exerts on the conversion degree of the resin cement can also be observed when evaluating the free radical concentration for samples obtained from the cervical, middle and apical 
T0

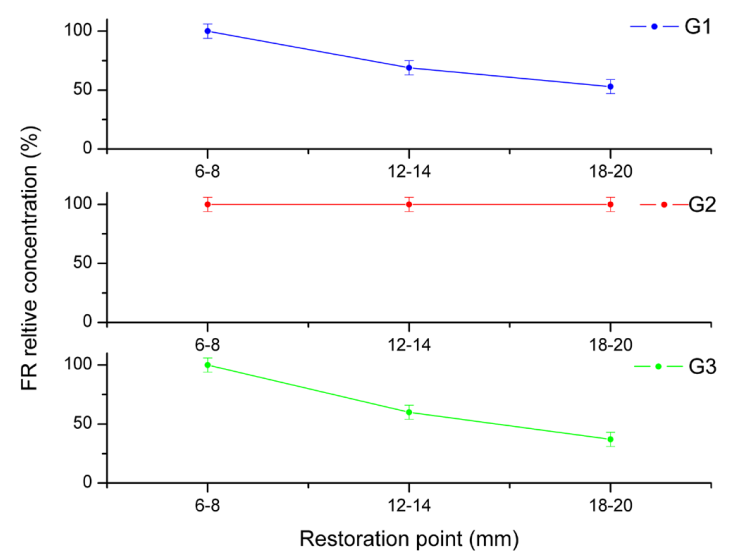

Figure 4. Relative concentration of free radicals at different restoration points in $\mathrm{T} 0$.

sections in G1, G2 and G3, and individually at T0 and T1 (Figures 4 and 5).

At T0 (Figure 4), the free radical concentration decreased for MT (12-14mm) and AT (18-20mm) in relation to CT (6-8mm) in $\mathrm{G} 1$ and $\mathrm{G} 3$. In G1, the initial free radical relative concentration is greater than in G3 because the radiation emitted by the curing light is transmitted by the post and the post-silicon interface ${ }^{24}$. This fact contributes to the facilitation of the polymerization of the resin cement; consequently, a faster conversion degree in G1 was observed (Figure 4), considering that the reaction was already started and a portion of the generated free radicals in G1 was already reacted at the time of observation. In turn, G2 did not show decreasing for CT, MT and AT, because the cement polymerization in all sections was exclusively chemical.

When analyzing points where the light incidence is relevant ten minutes after mixing base paste and catalyst (CT, Table 3), it is possible to notice that the light can duplicate the concentration of free radicals at these points. Analyzing Figure 4 it is possible to see that the concentration of free radicals decreased about $50 \%$ from CT to AT, for G1 and $\mathrm{G} 3$, such that it is possible to conclude that the light does not reach the deepest points of the restoration.

Twenty four hours after cementation (Figure 5), G1 showed greater decrease in relative concentration of free radicals with depth compared to G3, opposite behavior shown in Figure 4. It occurs because in T0 greater amount of free radicals are generated in G1 than that in G3, which affects the conversion degree. As greater the amount of free radicals generated greater is the conversion degree.

\section{References}

1. Faria ACL, Rodrigues RCS, de Almeida Antunes RP, de Mattos MG and Ribeiro RFJ. Endodontically treated teeth: characteristics and considerations to restore them. Journal of Prosthodontic Research. 2011; 55(2):69-74. http://dx.doi. org/10.1016/j.jpor.2010.07.003. PMid:20709618.

2. Cagidiaco MC, Goracci C, Garcia-Godoy F and Ferrari M. Clinical studies of fiber posts: a literature review. The

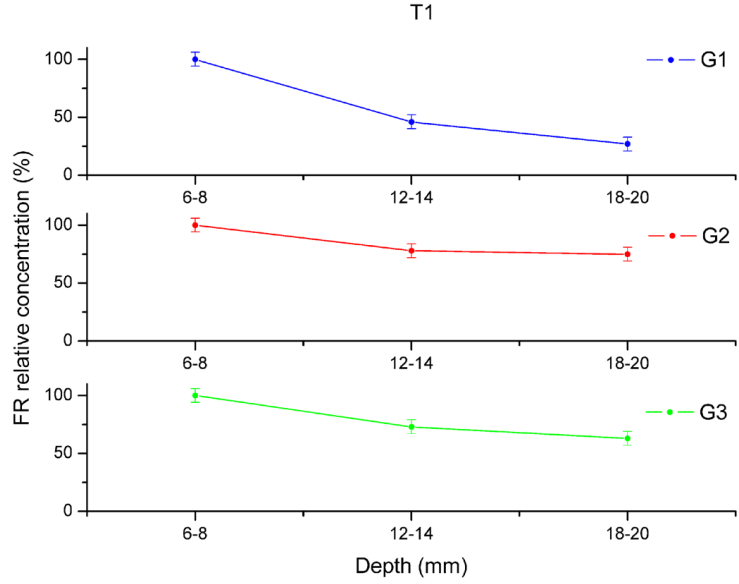

Figure 5. Relative concentration of free radicals at different restoration points in $\mathrm{T} 1$.

The decay rate of concentration of initiators depends on the initial concentration of initiators ${ }^{19}$.

The irradiation time, radiation power and distance from the curing device to the irradiated region directly influence the conversion degree and, consequently, the mechanical properties of a cement and in the bond strength of the fiberglass post to the radicular dentin ${ }^{5,8,21}$. Other variables that can influence the amount of generated free radicals and the conversion degree are the post diameter, arrangement of the fibers, composition, translucence degree and the cementation line thickness $^{12,25-27}$. In the present experiment, the power and time were kept constant, $1,500 \mathrm{~mW} / \mathrm{cm}^{2}$ and $40 \mathrm{~s}$, respectively, as well as the distance from the curing device to the cemented post. However, based on the present results, a reduction of the luminous intensity with increasing depth of a simulated root canal was observed.

\section{Conclusion}

The initial concentration of free radicals was influenced by the irradiation protocol of the cement only up to $8 \mathrm{~mm}$ of photopolymerization depth; therefore, polymerization in the apical third of a simulated root canal is only chemically initiated. Based on the current results, it is possible to conclude that light transmission of the post was significant for the first $8 \mathrm{~mm}$ of restoration fiberglass post, and is non-existent in the deepest points of a simulated root canal.

\section{Acknowledgements}

Authors thanks to FGM (Joinvile, SC, Brazil) by dental materials support.

International Journal of Prosthodontics. 2008; 21(4):328-336. PMid:18717092.

3. Tay FR, Loushine RJ, Lambrechts P, Weller RN and Pashley DH. Geometric factors affecting dentin bonding in root canals: a theoretical modeling approach. Journal of Endodontics. 2005; 31(8):584-589. http://dx.doi.org/10.1097/01.don.0000168891.23486. de. PMid:16044041.

4. Gomes GM, Gomes OMM, Reis A, Gomes JC, Loguercio AD and Calixto AL. Regional bond strengths to root canal dentin 
of fiber posts luted with three cementation systems. Brazilian Dental Journal. 2011; 22(6):460-467. http://dx.doi.org/10.1590/ S0103-64402011000600004. PMid:22189640.

5. Macedo VC, Faria e Silva AL and Martins LRM. Effect of cement type, relining procedure, and length of cementation on pull-out bond strength of fiber posts. Journal of Endodontics. 2010; 36(9):1543-1546. http://dx.doi.org/10.1016/j.joen.2010.04.014. PMid:20728724.

6. Goracci $\mathrm{C}$ and Ferrari M. Current perspectives on post systems: a literature review. Australian Dental Journal. 2011;56(1, Suppl 1):77-83. http://dx.doi.org/10.1111/j.1834-7819.2010.01298.x. PMid:21564118.

7. Braga RR, Cesar PF and Gonzaga CC. Mechanical properties of resin cements with different activation modes. Journal of Oral Rehabilitation. 2002; 29(3):257-262. http://dx.doi. org/10.1046/j.1365-2842.2002.00821.x. PMid:11896842.

8. Roberts HW, Leonard DL, Vandewalle KS, Cohen ME and Charlton DG. The effect of a translucent post on resin composite depth of cure. Dental Materials. 2004; 20(7):617-622. http:// dx.doi.org/10.1016/j.dental.2003.10.004. PMid:15236935.

9. Yoldas $\mathrm{O}$ and Alaçam T. Microhardness of composites in simulated root canals cured with light transmitting posts and glass-fiber reinforced composite posts. Journal of Endodontics. 2005; 31(2):104-106. http://dx.doi.org/10.1097/01. DON.0000133160.08600.47. PMid:15671819.

10. Calixto LR, Bandéca MC, Clavijo V, Andrade MF, Vaz LG and Campos EA. Effect of resin cement system and root region on the push-out bond strength of a translucent fiber post. Operative Dentistry. 2012; 37(1):80-86. http://dx.doi.org/10.2341/11035-L. PMid:21942240.

11. Shadman N, Atai M, Ghavam M, Kermanshah $\mathrm{H}$ and Ebrahimi SF. Parameters affecting degree of conversion of dual-cure resin cements in the root canal: FTIR analysis. Journal of the Canadian Dental Association. 2012; 78:c53. PMid:22673217.

12. Ceballos L, Garrido MA, Fuentes V and Rodríguez J. Mechanical characterization of resin cements used for luting fiber posts by nanoindentation. Dental Materials. 2007; 23(1):100-105. http:// dx.doi.org/10.1016/j.dental.2005.12.007. PMid:16430956.

13. Fontes AS, Sano W, Dall'Antonia LH and Di Mauro E. EPR in the characterization of the shade effect on translucence, remaining free radicals, and polymerization depth of commercially available resin composites. Applied Magnetic Resonance. 2010; 39(4):381-390. http://dx.doi.org/10.1007/s00723-010-0172-6.

14. Bullock AT and Sutcliffe LH. ESR spectra of free radicals derived from polymethylmethacrylate. Transactions of the Faraday Society. 1964; 8:625-633. http://dx.doi.org/10.1039/ tf9646000625.

15. Ottaviani MF, Fiorini A, Mason PN and Corvaja C. Electron spin resonance studies of dental composites: effects of irradiation time, decay over time, pulverization, and temperature variations. Dental Materials. 1992; 8(2):118-124. http://dx.doi. org/10.1016/0109-5641(92)90066-L. PMid:1325929.

16. Sustercic D, Cevc P, Funduk N and Pintar MM. Determination of curing time in visible-light-cured composite resins of different thickness by electron paramagnetic resonance. Journal of Materials Science. Materials in Medicine. 1997; 8(8):507-510. http://dx.doi.org/10.1023/A:1018534428200. PMid:15348718.

17. Menezes MA and Muench A. Dureza Knoop de resinas compostas em função do número relativo de radicais livres. Revista de Odontologia da Universidade de Sao Paulo. 1998; 12(3):281285. http://dx.doi.org/10.1590/S0103-06631998000300015.

18. Sano W and Mello CBM. Dureza das resinas odontológicas e quantidade de radicais determinadas por ESR. Revista Brasileira de Engenharia Biomédica. 1999; 15:17-20.

19. Lovell LG, Berchtold KA, Elliott JE, Lu H and Bowman $\mathrm{CN}$. Understanding the kinetics and network formation of dimethacrylate dental resins. Polymers for Advanced Technologies. 2001; 12(6):335-345. http://dx.doi.org/10.1002/pat.115.

20. Faria e Silva AL, Arias VG, Soares LES, Martin AA and Martins LRM. Influence of fiber-post translucency on the degree of conversion of a dual-cured resin cement. Journal of Endodontics. 2007; 33(3):303-305. http://dx.doi.org/10.1016/j. joen.2006.11.015. PMid:17320720.

21. Morgan LFSA, Peixoto RTRC, Albuquerque RC, Santos Corrêa MF, Poletto LTA and Pinotti MB. Light transmission through a translucent fiber post. Journal of Endodontics. 2008; 34(3):299-302. http://dx.doi.org/10.1016/j.joen.2007.12.007. PMid:18291280.

22. Leprince JG, Leveque P, Nysten B, Gallez B, Devaux J and Leloup G. New insight into the "depth of cure" of dimethacrylate-based dental composites. Dental Materials. 2012; 28(5):512-520. http://dx.doi.org/10.1016/j.dental.2011.12.004. PMid:22217607.

23. Fontes AS, Vicentin BLS, Valezi DF, Costa MF, Sano W and Di Mauro EA. Multifrequency (X-, Q-, and W-band) EPR and DFT Study of a Photopolymerizable Dental Resin. Applied Magnetic Resonance. 2014; 45(7):681-692. http://dx.doi. org/10.1007/s00723-014-0546-2.

24. Mallmann A, Jacques LB, Valandro LF and Muench A. Microtensile bond strength of photoactivated and autopolymerized adhesive systems to root dentin using translucent and opaque fiber-reinforced composite posts. The Journal of Prosthetic Dentistry. 2007; 97(3):165-172. http://dx.doi.org/10.1016/j. prosdent.2007.01.008. PMid:17394915.

25. Zorba YO, Erdemir A, Turkyilmaz A and Eldeniz AÜ. Effects of different curing units and luting agents on push-out bond strength of translucent posts. Journal of Endodontics. 2010; 36(9):1521-1525. http://dx.doi.org/10.1016/j.joen.2010.04.026. PMid:20728720.

26. Marchi AM No, Steinhaus J, Hausnerova B, Moeginger B and Blümich B. Time resolved study of the photo-curing process of dental resins with the NMR-MOUSE. Applied Magnetic Resonance. 2013; 44(9):1027-1039. http://dx.doi.org/10.1007/ s00723-013-0458-6.

27. Ricketts DNJ, Tait CME and Higgins AJ. Tooth preparation for post-retained restorations. British Dental Journal. 2005; 198(9):533-541. http://dx.doi.org/10.1038/sj.bdj.4812300. PMid:15895045. 